\title{
Information System Success Framework based on Interpersonal Conflict Factors
}

\author{
Mohammed Aboaoga ${ }^{1}$, Mohd Juzaiddin Ab Aziz ${ }^{2}$, Ibrahim Mohamed ${ }^{3}$ \\ ${ }^{1}$ Departement of Managemnet Information System, University Kebangsaan Malaysia, Malaysia \\ ${ }^{2}$ Center for Artificial Intelligence Technology (CAIT), University Kebangsaan Malaysia, Malaysia \\ ${ }^{3}$ Center for Software Technology and Management (SOFTAM), University Kebangsaan Malaysia, Malaysia
}

\begin{tabular}{l} 
Article Info \\
\hline Article history: \\
Received Jul 5, 2018 \\
Revised Sep 12, 2018 \\
Accepted Sep 19, 2018 \\
\hline
\end{tabular}

\section{Keyword:}

Disagreement

Financial sector

Information system success

interference

Instability

\begin{abstract}
Information system success (ISS) has received considerable attention from researchers as it plays an important role in improving the efficiency and productivity of an organization. Several researchers have conducted empirical studies using numerous factors (e.g. organizational, technological, and individual factors) which affect the information system success. However, there are several factors which are related to interpersonal conflict which may affect information system success. The interpersonal conflict is a critical dimension which can greatly influence information system success in a competitive environment such as the financial sector. Therefore, this study introduces a framework to investigate the influence of interpersonal conflict factors on information system success in the Ministry of Finance, Yemen. The study employed a quantitative method which consists of the following steps: survey design, data collection and data analysis. A sample size comprising 130 employees were distributed in the Ministry of Finance, Yemen. Questionnaires were used to collect data from this sample. Data analysis (reliability, validity, correlation and factor analysis) has been carried out using SPSS. In addition, structural equation modelling (SEM) has been used for evaluation the research model. Based on the experimental results, the findings in this study revealed that the interpersonal factors (interference, disagreement and instability) significantly negatively (at 0.05 level of significance) influence user satisfaction of information system success.
\end{abstract}

Copyright $@ 2018$ Institute of Advanced Engineering and Science. All rights reserved.

\section{Corresponding Author:}

Mohammed Aboaoga, Faculty of Information Science and Technology,

University Kebangsaan Malaysia, 43600 UKM, Bangi, Selangor, Malaysia.

Email: abuauja@siswa.ukm.edu.my

\section{INTRODUCTION}

Information system (IS) is one of the important points which lead to the success of an organization, especially an organization that requires management and financial processing [1]. The success of the information system is also important not only for organizations to improve their efficiency and productivity, but also for developers who are responsible for enhancing and improving the systems. Therefore, the main challenge is how to assess the information system success based on user perception. Previous studies have investigated the factors that can be used to measure the IS success based on the users' perception [2]-[5].

Most of the prior researches in the field of IS success have focused mainly on information quality, system quality, service quality, perceived usefulness, user satisfaction, user perception, and also organizational and technological factors [3], [6], [7]. Other researches consider interpersonal conflict [8]-[10] factors as important predictors of the success in the information system development. However, limited number of studies have been conducted to examine the effects of these factors on IS success. 
In general, the term of Interpersonal conflict (IPC) as an event that occurs between -at least- two individuals in the course of interactions due to the contradictions of values, goals, expectations and perception of personal differences. It has been widely investigated as an important dimension which has an influence on different dimensions in many social [11]-[13] and technological [4], [10], [14] fields. The outputs of these researches were inconclusive; while some researchers [15] pointed out that it can be constructive indicators, other researches demonstrated that it can lead to negative impact on some dimensions such as organizational performance [16], [17].

Therefore, this study would mainly introduce a proposed framework which focuses on interpersonal conflict factors which have an influence on IS success. The proposed framework depends on the well-defined IS success model (DeLone-McLean, 2003). In addition, we introduce the interpersonal conflict factors that have not been sufficiently examined, especially in developing countries as in Yemen. These interpersonal conflict factors include: interference, disagreement and instability. The proposed framework has been validated throughout the quantitative method.

\section{THEORETICAL FRAMEWORK}

This section presents the proposed framework for the influence of IPC factors on information system success. More specifically, this framework is to examine the effect of the IPC factors and technological factos on the user satisfaction. Figure 1 shows the proposed framework in this research.

\subsection{Technological factor}

According to several studies[18]-[20] the technological dimension includes three main factors: information quality, system quality and service quality. These studies pointed that these factors have a positive influence on user satisfaction. Following these studies, the hypotheses in this work have been formulated to link the relations between technological factors and user satisfaction.

The technological dimension is defined by how well the information, systems, and services match the needs of the users. It describes the quality of a system in terms of the quality of the information as a product of the system, the quality of the system that provides the information, and the quality of the service provided by the system [21], [22]. According to [18], technological dimension is the most important part of the IS success theory. Since the effectiveness of IS is the degree to which the information system is successful in producing the desired purpose, it is thus directly proportional to the technological dimension.

Previous study [7] have indicated that technological factors are very important in examining IS success [6], [19], [23]. Information quality is concerned with the goodness and accuracy of the output from the users' perspective (e.g. reports, analysis, and decision making). System quality refers to factors which measure the system's properties such as, consistency, usability, reliability, convenience of access, flexibility, integration, response time, and language [24], [18]. Service quality is the quality of the support that IS users receive from the service provider such as tangibility, reliability, responsiveness, assurance, and empathy [20].

\subsection{Interpersonal conflict (IPC) factors}

The investigated in this study, which are the bases for formulating a proposed framework, are the most appropriate and relevant to the interpersonal conflict factors and definitions obtained from the literature. Researchers in previous related studies identified and recognized two factors of interpersonal conflict (IPC). These factors are interference and disagreement [9],[11]. Furthermore, according to [25] instability considered factor representing the causal factors of interpersonal conflict. For IS success, previous studies demonstrated that the interpersonal conflict has relationship with user satisfaction. The following section will discuss these factors.

\subsubsection{Interference}

Interference is one of the key factors of interpersonal conflict, which is related to the existence of interference between users in terms of their tasks, objects, and goals [9]. That means, it resulted in behavioral attributes. Researchers believe that the key process of interpersonal conflict is the behavior where one or more disputants oppose their counterpart's interests or goals [26].

The best way to reduce the bad effects of interference within organizations is therefore to show it as an important factor of IS success. Any organization should include a good perception of interference among its staff as apart not parcel from its culture. Again this research will deal with this concept as a constructive concept which have a role of IS success looking for the factors which create this type of conflict between users in terms of their tasks, objects, and goals in organization. In addition, this research also will examine the impacts of this factor on IS success through user satisfaction. 


\subsubsection{Disagreement}

Disagreement is a term which refers to the divergence of values, needs, interests, opinions, goals, or objectives among users. It considered the key cognitive component of interpersonal conflict. Every company have its rules and regulations that organize its staff, therefore it is not sufficient for conflict to emerge among users because there are different situations where individuals can get into contradictions in values or even opinions which not consider important or relevant to IS success like interpersonal conflict [27]. In this research, disagreement refers the varieties among users in terms of their values, needs, interests, opinions, and goals in organization which will be examined as the construct of the conflict and its impact on IS success.

Many researches have confirmed that disagreement is a main form of the interpersonal conflict that top management have to handle it in the organization, given the highly interpersonal nature of the managerial role [28], [29]. Some researches [30], [14] stated that the disagreement is a serious issue for the employees as it deeply affects behavior emotions. Another researches [28], [29] found that the disagreement has a strong negative influence on the outcomes of organization (organization performance). Adomi and Ozioma Anie [31] also indicated that the disagreement can generate a sequence of conditions which lead to the aggressive behavior and disorder.

\subsubsection{Instability}

The instability is defended as the situation to the continuous changes in the authorizations, procedures and tasks by senior and direct management. Aslam [32] pointed out that instability has an influence on the employees' work behavior within the IS organization. Alfaadel, et al. [33] found the conflict and the instability (politics) are the most important factors that lead to the IT projects failure. Liu, et al. [14] study proposed that the degree of requirements instability is positively associated with interpersonal conflict which, in turn, increases requirements diversity and thus affects the final project outcomes. Based on this observation, this study assumes that there is direct relationship between instability with user satisfaction. Regarding to information system success, the instability factor refers to the ability of the IS to deal with the continuous changes of top management in the organizations. Elmagri [25] investigated the administrative instability as a factor which causes the interpersonal conflict in the organization. The administrative instability in organizations results in many psychological stresses on workers such as unstable organizational structures, redesigned jobs, and unstable management policies.

\subsection{User satisfaction}

According to [23], the term user satisfaction (US) refers to the factor which measures the degree to which the users are satisfied with the IS. In IS success studies, user satisfaction is the most widespread factor for measuring the information systems success, effectiveness, acceptance [24], [34] and Stakeholders [35], [36]. Thus, the hypotheses have been formulated based on previous studies to investigate the relations among user satisfaction, technological factors and interpersonal conflict factors

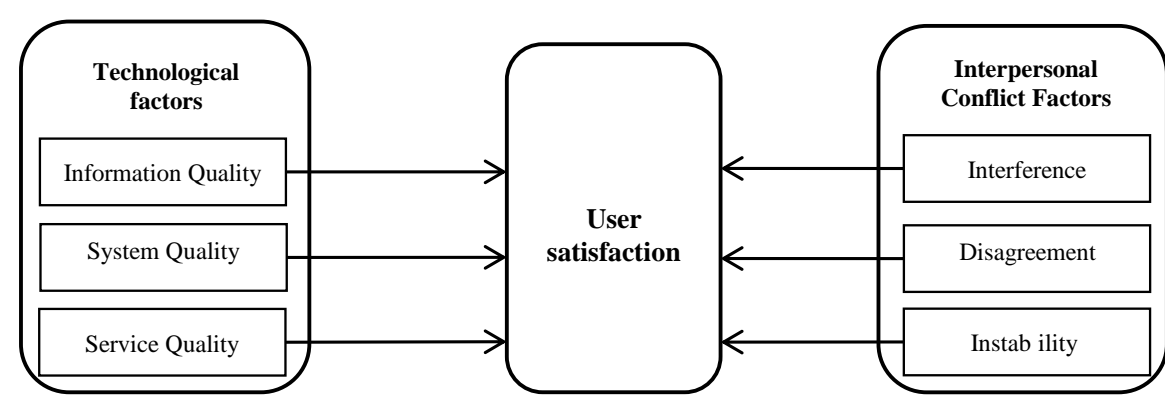

Figure 1. Proposed framework

\section{RESEARCH METHOD}

The study employed quantitative methods. Firstly, the questionnaire has been designed based on the previous studies [9]. Then, it has been translated to Arabic as the target sample is the employees in Yemen. To avoid any ambiguity, the questionnaire has been validated by experts. A sample size comprising 130 employees were selected from four financial organizations using stratified random sampling. Questionnaires were used to collect data which was validated through a pilot test while reliability was measured using the 
Cronbachees Alpha. Finally, SPSS and structural equation modelling (SEM) were used for data analysis and evaluation of the research model.

\section{RESULTS AND ANALYSIS}

Firstly, as in most researches which use the quantitative method, the collect data must be examined using two important measures: reliability and validity. In this research, the reliability has been measured using the Cronbach's Alpha which is the metric returns value between 0 (very low reliability) to 1 (very high reliability). The validity of the data has been computed using the kaiser meyer olkin (KMO) test which reflects the sampling adequacy. For each factor, this test returns value between 0 and 1 , in which the sampling is adequate if this value is more than 0.8 . For all data, Table 1 reports the result of reliability and validity for each factor.

Table 1. Reliability and Validity Test Results using Cronbach's alpha and KMO

\begin{tabular}{ccll}
\hline Item & Number of items & Cronbach's alpha & KMO \\
\hline IQ & 5 & .894 & .855 \\
SQ & 5 & .881 & .875 \\
SrQ & 4 & .949 & .867 \\
IFC & 6 & .976 & .909 \\
DSAG & 5 & .830 & .742 \\
INSTB & 5 & .911 & .862 \\
US & 5 & .962 & .865 \\
\hline
\end{tabular}

Secondly, we used the correlation coefficient in order to measure the association among the investigated factors. Pearson's correlation is a metric which measures the linear relationship between two lists of variables. A correlation analysis is used to clarify that the independent variable contributes information for predicting the dependent variable.

In this study, the goals of the correlation analysis are to measure the relationship between the independent and dependent factors, and the relationship among the independent factors. Table 2 shows the correlation analysis result between independent and dependent factors.

Table 2. The Correlation Analysis between Independent and Dependent Factors

\begin{tabular}{cccccccc}
\hline & IQ & SQ & SrQ & IFC & DSAG & INSTB \\
\hline IQ & 1 & $.463^{* *}$ & $.664^{* *}$ & $-.671^{* *}$ & .014 & $-.404^{* *}$ \\
SQ & & 1 & $.371^{* *}$ & $-.565^{* *}$ & .011 & $-.431^{* *}$ & $.523^{* * *}$ \\
SrQ & & & 1 & $-.643^{* *}$ & .036 & $-.449^{* *}$ & $.626^{* *}$ \\
IFC & & & & 1 & .002 & $.550^{* *}$ \\
DSAG & & & & & $-.739^{* *}$ \\
INSTB & & & & & -.047 & 1 \\
US & & & & & -.032 \\
\hline
\end{tabular}

*Correlation is significant at the 0.05 level (2-tailed).

**Correlation is significant at the 0.01 level (2-tailed).

Structural equation modeling (SEM) purposes to explain the relationships among multiple variables. In this study, SEM is used to analyze hypotheses relationships linking the model constructs. According to Hair, et al. [37] the SEM is most useful technique which testing the complex relationship and measure the strength among item from each independents variables and dependent variables of the research model. For this purpose, confirmatory factor analysis (CFA) using AMOS 23 was performed. Following this, the paths or causal relationships between the exogenous and endogenous constructs were specified in the structural model.

\section{SUMMARY OF FINDINGS}

From the Table 1 the Cronbach's Alpha of investigated factors in this research is ranging from 0.830 to 0.976. Hinton, et al. [38] suggested four different levels of reliability: an excellent level range (0.90 and above), a high level range (0.70 to 0.90$)$, a moderate level range (between 0.50 and 0.70 ) and a low level ( 0.50 and below). From the same table, the value of KMO was distributed between 0.742 and 0.909. [37] pointed out that, the KMO value with 0.90 is excellent; 0.80 is good; 0.70 is middling; 0.60 is mediocre; 0.50 is acceptable but miserable; and below 0.50 is unacceptable.

The experimental results from Table 2 can be analyzed from two points of views. From perspective of interpersonal conflict factors, the result showed that there is a significant correlation among these

Information System Success Framework based on Interpersonal Conflict Factors (Mohammed Aboaoga) 
independent factors. This supports our measurement of interpersonal conflict dimension using these factors. In other side, the independent factors are negatively correlated to dependent factor (user satisfaction). In addition, the highest correlation was between interference and user satisfaction $(-.739 * *)$. This is due to the nature of the interference in the financial procedures which usually require hierarchical operations through different sections This is due to the critical situation in Yemen which faced the instability during the doing the study. Based on Figure 1 the results of the path analysis showed that all hypotheses are significant (level > 0.05). In fact, this strengthens our hypotheses that interpersonal conflict factors negatively influence organizational performance in financial sector.

From Figure 2 which depicts the the structural model (Goodness of Fit Indices), it is clear that this model fit all indices. The values of the indices mean the model is a good fit to the data, in which these valures of $\chi 2$, CFI, TLI and IFI in the model were 1.491, 0.961, 0.955, and 0.961 respectively. In addition, the RMSEA of the model is 0.62 which is the better measurement.

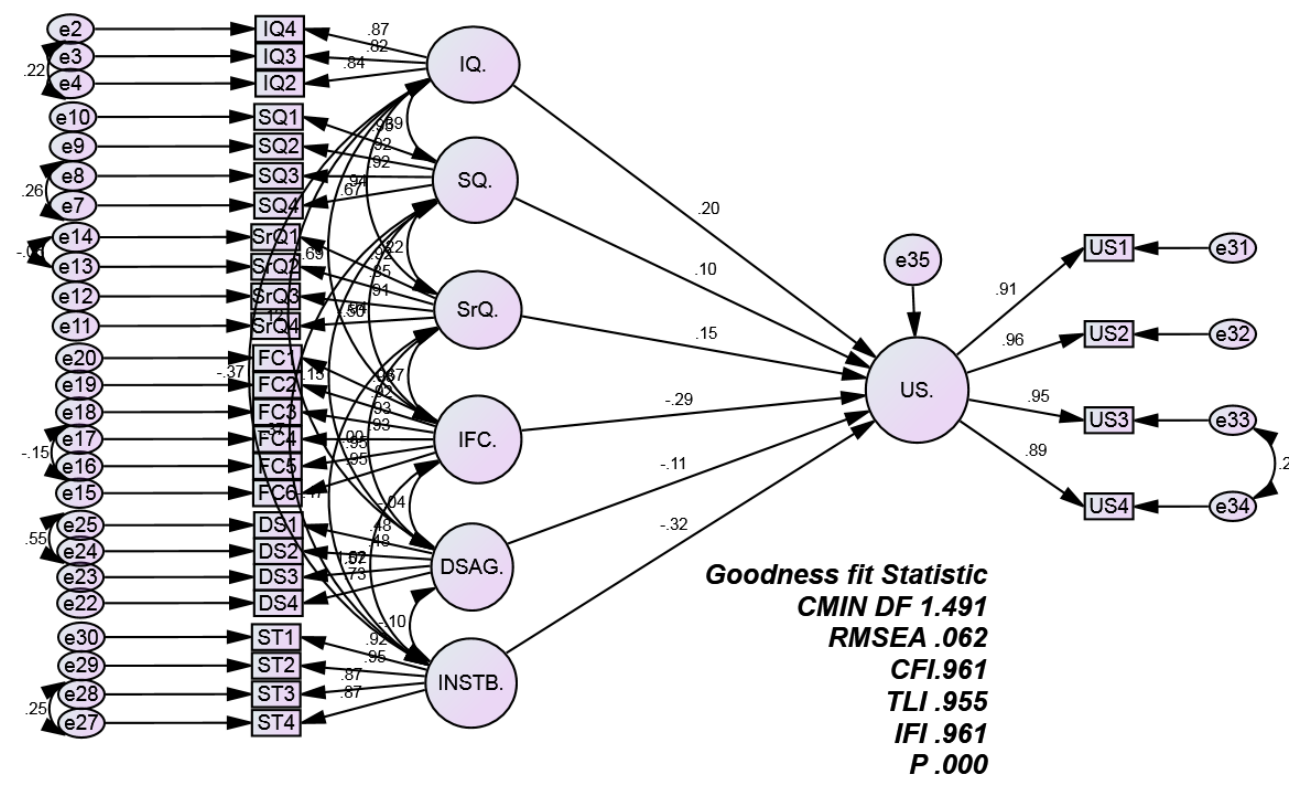

Figure 2. Structural model

This study suggested that technological factors has direct and positive impact on user satisfaction. Several previous studies on IS success [7], [23], [39] have elucidate the argument that higher degree of technological quality leads to enhanced user satisfaction. The statistical findings in this research indicate that technological factors (IQ, SQ and SrQ) have a postive significant impact on user satisfaction. This result is consistent with the past studies [7], [40], [41]. On other hand, this study also suggested that interpersonal conflict factors has direct and negative impact on user satisfaction. Several studies [42], [43] pointed out the argument that lowes degree of interpersonal conflict leads to enhanced user satisfaction. Thus, the statistical findings in this research indicate that interpersonal conflict factors (interference, disagreement and instability) have a negative significant impact on user satisfaction.

Based on the results, the respondents' instability to interpersonal conflict in this model revealed a strongest negative influence their user satisfaction. In the fact, this significant hypothesis that continuous changes in the management leads to dissatisfaction in the public financial sector.

Interference pointer consider the second construct of the model has a strong negative and statistically significant influence user satisfaction in the public financial sector. Thus, interference was considered an obstacle for IS success and leaded to delay in accomplishing tasks in Yemeni public financial sector.

\section{CONCLUSION}

In this study we proposed framework which investigated influence of technological and interpersonal conflict on user satisfaction of information system success. The proposed framework has been 
validated using the data that has been collected from a financial organization in Yemen. The empirical results reveled that two technological factors (information quality and service quality) have a significant positive effect on user satisfaction, whilst, the system quality has insignificant effect on user satisfaction. Although the information system used in the financial sector in Yemen are subject to international standards, the results of this study indicate the urgent need to make adjustments to the systems to overcome the issues and problems resulting from interpersonal conflict. This is due to that interpersonal conflict factors have negative effect on user satisfaction in public financial sector in Yemen. This effect was statistically significant at the 0.05 level of significant. The finding of this study can be regarded as a fundamental for future strategies in improving a user satisfaction at the Ministry of Finance in Yemen. This framework can be extended to include factors that avoid and manage the interpersonal conflict in the organization.

\section{ACKNOWLEDGEMENTS}

The authors would like to thank Faculty of Information Sciences and Technology UKM for help. In addition, thank the employees of the Ministry of Finance (MOF) of Yemen for their support.

\section{REFERENCES}

[1] M. Romi Ismail, "Organizational Culture Impact on Information Systems Success", Computer Science and Software Techniques in 2011, vol. 42, 2011.

[2] G. Whyte, et al., "Understanding user perceptions of information systems success," The Journal of Strategic Information Systems, vol. 6, pp. 35-68, 1997.

[3] R. Moh'd Al-adaileh, "An evaluation of information systems success: A user perspective-the case of Jordan Telecom Group", European Journal of Scientific Research, vol. 37, pp. 226-239, 2009.

[4] Y. H. Al-Mamary, et al., "Factors Affecting Successful Adoption Of Management Information Systems In Organizations Towards Enhancing Organizational Performance", American Journal of Systems and Software, vol. 2, pp. 121-126, 2014

[5] A. R. Ahlan, "Implementation of input-process-output model for measuring information system project success", Indonesian Journal of Electrical Engineering and Computer Science, vol. 12, pp. 5603-5612, 2014.

[6] Y. H. Al-Mamary, et al., "Investigating the Key Factors Influencing on Management Information Systems Adoption among Telecommunication Companies in Yemen: The Conceptual Framework Development", International Journal of Energy, Information and Communications, vol. 6, pp. 59-68, 2015.

[7] S. A. Hussein, "An empirical investigation of information systems success. An analysis of the factors affecting banking information systems success in Egypt", University of Bradford, 2010.

[8] D. Robey, et al., "Perceptions of Conflict And Success In Information Systems Development Projects," Journal of Management Information Systems, vol. 10, pp. 123-140, 1993.

[9] H. Barki and J. Hartwick, "Interpersonal Conflict and its Management in Information System Development", Mis Quarterly, pp. 195-228, 2001.

[10] G. Moeller, et al., "Understanding Antecedents of Interpersonal Conflict in Information Systems Development: A Critical Analysis", Journal of Information Technology Management, vol. 23, pp. 12-43, 2012.

[11] I. Khan, et al., "The Interpersonal Conflicts and its impact on the Employees' Morale in the HEIs: A correlative study".

[12] W. A. El-Hosany, "Interpersonal Conflict, Job Satisfaction, and Team Effectiveness Among Nurses at Ismailia General Hospital", Journal of Nursing Education and Practice, vol. 7, p. 115, 2016.

[13] M. Shah, "Impact of Interpersonal Conflict in Health Care Setting on Patient Care; the Role of Nursing Leadership Style on Resolving the Conflict", Nurse Care Open Acces J, vol. 2, p. 00031, 2017.

[14] J. Y.-C. Liu, et al., "Relationships among Interpersonal Conflict, Requirements Uncertainty, and Software Project Performance", International Journal of Project Management, vol. 29, pp. 547-556, 2011.

[15] H. Weihrich and H. Koontz, "Management: A global perspective." New York: McGraw-Hill, Inc", 1994.

[16] M. Eunice, et al., "Effects of interpersonal conflict on organisational performance in selected hotels in Kisiitown, Kenya", African Journal of Hospitality, Toursim and Leisure., vol. 4, no. 1, 2014.

[17] I. U. Haq, "The impact of interpersonal conflict on job outcomes: mediating role of perception of organizational politics", Procedia-Social and Behavioral Sciences, vol. 25, pp. 287-310, 2011.

[18] W. H. Delone and E. R. McLean, "The DeLone and McLean model of information systems success: a ten-year update", Journal of management information systems, vol. 19, pp. 9-30, 2003.

[19] P. B. Seddon, "A respecification and extension of the DeLone and McLean model of IS success", Information systems research, vol. 8, pp. 240-253, 1997.

[20] S. Petter, et al., "Measuring Information Systems Success: Models, Dimensions, Measures, and Interrelationships", European Journal of Information Systems, vol. 17, pp. 236-263, 2008.

[21] M. Ge, et al., "Information Quality Assessment: Validating Measurement Dimensions and Processes", in ECIS, 2011, p. 75.

[22] K. A. Eldrandaly, et al., "A Model for Measuring Geographic Information Systems Success", Journal of Geographic Information System, vol. 7, p. 328, 2015. 
[23] S. Petter, et al., "Information Systems Success: The Quest for the Independent Variables", Journal of Management Information Systems, vol. 29, pp. 7-62, 2013.

[24] J. E. Bailey and S. W. Pearson, "Development of a Tool for Measuring and Analyzing Computer User Satisfaction", Management Science, vol. 29, pp. 530-545, 1983.

[25] M. Elmagri, "The Causal Factors of Interpersonal Conflict in the Libyan Cement Industry", University of Salford, 2014.

[26] J. A. Wall and R. R. Callister, "Conflict and its Management", Journal of Management, vol. 21, pp. 515-558, 1995.

[27] D. U. Gilbert, Konfliktmanagement in international tätigen Unternehmen: Ein diskursethischer Ansatz zur Regelung von Konflikten im interkulturellen Management: Verlag Wiss. \& Praxis, 1998.

[28] D. Rollinson, Organisational behaviour and analysis: An integrated approach: Pearson Education, 2008.

[29] D. Wood, et al., "Identification and Measurement of a More Comprehensive Set of Person-Descriptive Trait Markers from the English Lexicon", Journal of Research in Personality, vol. 44, pp. 258-272, 2010.

[30] J. W. Newstrom, Organizational Behaviour-Human Behaviour at work (12th ed), New York: McGraw Hill International Edition., 2007.

[31] E. E. Adomi and S. Ozioma Anie, "Conflict Management in Nigerian University Libraries", Library Management, vol. 27, pp. 520-530, 2006.

[32] M. Aslam, et al., "Effect on Organizations and Quality due to Changed Employee Work Behaviors caused by Political Instability in Developing Countries (A case study of Pakistan's ICT sector)", 11th QMOD Conference. Quality Management and Organizational Development,Attaining Sustainability From Organizational Excellence to SustainableExcellence; in Helsingborg; Sweden, pp. 783-793, 2008.

[33] F. Alfaadel, et al., "Success and Failure of IT Projects: A Study in Saudi Arabia", in Proceedings of the 11th WSEAS international conference on Applied Computer and Applied Computational Science, 2012, pp. 77-82.

[34] A. Rai, et al., "Assessing the Validity of IS Success Models: An Empirical Test and Theoretical Analysis", Information Systems Research, vol. 13, pp. 50-69, 2002.

[35] A. R. A. R. Ahlan, et al., "The User Satisfaction Perspectives of the Information System Projects", Indonesian Journal of Electrical Engineering and Computer Science, vol. 4, pp. 215-223, 2016.

[36] A. R. Ahlan, et al., "Measurement of Information System Project Success based on Perceptions of the Internal Stakeholders", International Journal of Electrical and Computer Engineering, vol. 5, p. 271, 2015.

[37] J. Hair, et al., Multivariate Data Analysis Seventh Edition Prentice Hall, 2010.

[38] P. R. Hinton, I. McMurray, and C. Brownlow, SPSS explained: Routledge, 2014.

[39] M. Visser, et al., "Evaluation of Management Information Systems: A Study at a Further Education and Training College", 2013.

[40] Y. H. Al-Mamary, et al., "Adoption of Management Information Systems in Context of Yemeni Organizations: A Structural Equation Modeling Approach", Journal of Digital Information Management, vol. 13, pp. 429-444, 2015.

[41] Y. W. Hung and S.-C. Hsu, "Understanding the Impacts of Information Quality, System Quality and Service Quality on Consumers' Satisfaction and Continuance Intention", in Service Science and Innovation (ICSSI), 2013 Fifth International Conference on, 2013, pp. 245-246.

[42] Ø. Sørebø, et al., "The Impact of Interpersonal Conflict Between Managers and Users on Information Systems Success During the Implementation of a New Information System," 2005.

[43] C. A. Demsky, Interpersonal conflict and employee well-being: The moderating role of recovery experiences: Portland State University, 2012. 